\title{
Ferramentas tecnológicas e sua realidade de uso em escolas das redes municipal e estadual de Passa Sete e Sobradinho
}

Elinara dos Santos Pontel

Resumo: Esta pesquisa está vinculada à introdução das novas ferramentas tecnológicas no ensino, através do planejamento pedagógico dos professores. Nesse enfoque foi feito um trabalho de pesquisa com o intuito de conhecer a realidade nas escolas estaduais e municipais de Passa Sete e Sobradinho-RS, abrangendo um total de cinco escolas de cada rede. Buscou-se ainda, suscitar nos líderes educacionais, indagações quanto ao que se está auxiliando o professor e o aluno na interação com as novas tecnologias, bem como servir de subsídio para aprimorar as práticas docentes numa apropriação significativa do uso das mesmas na educação. $\mathrm{O}$ estudo evidenciou que a maioria das escolas possui laboratório de informática com acesso à Internet, sendo pouco usado pelos professores em suas práticas pedagógicas e em projetos voltados para a aprendizagem e uso das tecnologias. Palavras-chave: Novas ferramentas tecnológicas; Educação; Práticas pedagógicas.

Abstract: This research is linked to the introduction of new technological tools in education through teachers' educational planning. In this approach, it was made a research work with intention to know the reality state and municipal schools of Passa Sete and Sobradinho, being five schools in each network.

* Professora de Educação Básica, Graduada em Letras (Português e Inglês). Especialista em Gestão Escolar numa Visão Psicopedagógica pela FacVest, Pós-Graduada em Mídias na Educação pela UFSM. E-mail: elinara.pontel@gmail.com 
Searched still, raise in educational leaders, questions about what they are assisting the teacher and student interaction with new technologies. As well as provide support to improve teaching practices in a meaningful appropriation of use themselves in education. The study showed that many schools have computer lab with access Internet, been little used by teachers in classrooms, as well as in projects come back to learning and use of the technologies.

Keywords: New technological tools; Education; Pedagogical practices.

\section{Introdução}

Novas tecnologias fazem parte da sociedade atual, e sua evolução é acompanhada pelas crianças e adolescentes. Percebe-se isso na naturalidade que utilizam celulares, câmeras fotográficas, computadores, vídeos, equipamento de som entre outros. E dentro dessa realidade encontram-se as escolas com suas práticas pedagógicas que de certa forma precisam se contextualizar às novas ferramentas de comunicação que favoreçam a busca de um conhecimento mais dinâmico e global.

Diante dessas questões que problematizam o assunto, este trabalho buscou conhecer a realidade de uso das novas tecnologias nas escolas municipais e estaduais pesquisadas, considerando os dados de cada rede no que tange projetos, envolvimento e diferenças dos referidos sistemas educacionais. Salientando as possibilidades de uso, oportunidades e estratégias de ensino providas em cada meio educacional.

Com o intuito de levantar dados que envolvem essa temática, foi realizada uma pesquisa de campo para obter-se uma visão mais nítida do uso da informática nas redes pesquisadas. Foram considerados os fatores relacionados ao acesso e provimento das tecnologias em nosso cotidiano na escola, bem como descobrir se há um trabalho diferenciado e atraente no campo de inclusão das novas tecnologias no ensino. 
$\mathrm{Na}$ verdade, o uso de ferramentas tecnológicas é um assunto que nos leva a inúmeros fatores que o permeiam. Além de prover o acesso é necessário que haja um envolvimento maior no sentido de auxiliar o seu uso na prática pedagógica. Com este trabalho busca-se descobrir tudo o que está sendo feito nas escolas pesquisadas e que isso sirva para contribuir e instigar ainda mais outras ações educativas no uso das novas mídias.

A segunda seção deste artigo versará sobre uma abordagem, baseada em autores renomados, sobre a importância do uso das ferramentas tecnológicas e suas possíveis contribuições para melhorar a aprendizagem do aluno e torná-lo inserido e atuante no mundo tecnológico. $\mathrm{Na}$ terceira, será feita uma análise da pesquisa exploratória realizada nas redes escolares municipais e estaduais da região escolhida envolvendo direção, supervisão e monitor de laboratório de informática, nos aspectos relevantes que envolvem o uso das tecnologias nas escolas. E para finalizar, a conclusão das discussões da pesquisa e contribuições sobre o uso das tecnologias no planejamento.

\section{Novas ferramentas na educação}

Vive-se a Era do Conhecimento alavancada pelos avanços tecnológicos que se impóem a cada organização social e a cada membro da população. Com isso surgem novos métodos, novas formas de se comunicar, organizar e buscar o conhecimento. Segundo Neves (2007, p. 217), "existem tempos nos quais os saberes, receitas, fórmulas e ferramentas que as pessoas tradicionalmente usam não são mais eficazes".

Nossa sociedade contemporânea está permeada de inovações, descobertas e novas tecnologias que vieram para ficar e transformar a realidade como num passe de mágica. Através de uma Webcan é possível se comunicar de forma tão rápida e eficiente com alguém que está até mesmo em outro país, e mais, por meio de programas interativos com o público até mesmo aparecer 
na TV, dar nossa opinião e votar em enquetes de determinados programas. Até pouco tempo atrás não imaginávamos realizar transações bancárias de nossas próprias casas, termos uma rede de amigos e sermos proprietários virtuais através de jogos como a Mini Fazenda ou Café Mania. E ainda participar de redes de relacionamento ou comunidades, e mais, que teríamos um local para postar nossos trabalhos e ideias na rede e eles pudessem ser visualizados por todos que viessem acessá-los.

Tudo o que foi citado acima, e muito mais, é possível realizar com a chegada da informática, suas ferramentas e programas. Através do computador e seus softwares é possível melhorar a apresentação de trabalhos, já o complemento vem com a ferramenta Internet que pode realizar inúmeras atividades virtuais de comunicação, leitura, escrita, pesquisa e publicação de textos. E toda essa tecnologia, já se encontra acessível; através das escolas, ambientes informatizados destinados ao uso da população ou nas próprias casas. A obra organizada por Coscarelli e Ribeiro (2008) apresenta um artigo do qual foi retirada a seguinte citação que vem ao encontro do que foi abordado:

[...] a Internet, seja com conexão discada ou em banda larga, deixou de ser luxo ou acessível apenas a grandes corporações e passou a ser também de uso dentro das casas das pessoas. Com a finalidade de estudar, pesquisar, comunicar, ter momentos de lazer ou de fazer um curso virtual, a Internet tornou-se uma nova ferramenta (COSCARELLI; RIBEIRO, 2008, p. 8).

Comentando essas ideias, Martins (2000) focaliza a relação emocional que a web proporciona e ainda faz uma relação entre as tecnologias mais interativas quando afirma:

Um aparelho de televisão é um receptor passivo, uma extremidade de rede, uma periferia. Um computador é um instrumento de troca, de produção e de estocagem de informações. Ao canalizar e entrelaçar múltiplos fluxos torna-se um centro virtual, instrumento de poder (MARTINS, 2000, p. 203).

Realmente um computador com conexão à rede gera um centro virtual no qual os usuários fazem suas pesquisas, participam 
de fóruns e cursos à distância, trocam e compartilham mensagens com seus amigos virtuais, participam de comunidades e de certa forma, o momento da diversão para muitos, passou a ser em frente ao computador, interagindo com os jogos que a rede proporciona. Todas essas tecnologias permitem que os usuários tenham inúmeras ferramentas de comunicação a apenas um clique. Uma comunicação mais versátil para quem dela tiver o conhecimento necessário para usá-la.

Sendo a escola uma entidade educacional que prima pelo desenvolvimento pleno do cidadão, cabe a ela contribuir para essa iniciação tecnológica. Frente a isso Mercado (2002) argumenta em sua obra que a escola precisa ensinar os alunos a utilizar e dominar as inovações tecnológicas, uma vez que foi evidenciado que o contato moderado e orientado da criança com o computador, em situações de ensino-aprendizagem, contribui para o seu melhor desenvolvimento cognitivo e intelectual. Em especial no que diz respeito ao raciocínio lógico e formal, e que toda essa interação com as tecnologias estimula no estudante o interesse na busca de novos conhecimentos, contribuindo para que essas atitudes e habilidades de inventar ou encontrar soluções para os problemas sejam mantidas ao longo da vida profissional.

$\mathrm{O}$ autor referido anteriormente ainda tece o seguinte comentário enfático em relação ao papel da escola quando afirma:

[...] a escola tem de preparar uma nova relação com o saber, muito diferente da que é praticada hoje, pois não basta os alunos relembrar as informações recebidas, terão que adquirir as habilidades de utilizálas e avaliá-las, construindo um pensamento reflexivo e crítico que é de grande importância para além da sala de aula (MERCADO, 2002, p. 138).

Diante dessa nova forma de aprender, o autor argumenta que "a tecnologia não resolve sozinha os problemas da educação" (Mercado, 2002, p. 138), esclarece ainda que as máquinas apenas complementam o ensino, e afirma que o papel do professor ganha maior importância, pois ele passa a ser o mediador da aprendizagem, apontando caminhos, esclarecendo dúvidas, propondo 
pesquisas e projetos, contribuindo para o aluno aprender muito mais.

Envolvendo a temática da elaboração de projetos, destacase o seguinte comentário de Konrath:

[...] penso que a primeira atitude importante de início é instigar o grupo envolvido a desenvolver as atividades do projeto, a partir disso todos são capazes de contribuir e assim construir seu conhecimento.

[...] favorecendo a integração entre as diferentes áreas de conhecimento e que para se trabalhar com projetos usando as novas mídias é importante que o professor compreenda como, por que, para que e quando integrar as mídias na prática pedagógica, potencializando no aluno novas formas de pesquisa e de apresentação dos resultados do projeto (KONRATH, 2008, p. 131-149).

E para que haja a interação do aluno com a máquina, Mercado (2000) afirma que é necessário o professor estar preparado para fazer a combinação do técnico com o pedagógico, de forma a compreender as perspectivas educacionais que estão nos softwares em uso, ou seja, as noções de ensino-aprendizagem e conhecimento, implícitos no software e assim entender por que e como integrar o computador na sua prática pedagógica.

Essas ferramentas e muitas outras que existem e ainda vão surgir fazem parte do cotidiano de inúmeras pessoas, principalmente da nova geração que fazem delas uma companheira inseparável. Diante do fato que as crianças tiveram o acesso às novas tecnologias desde a infância, pode facilitar a sua integração e uso, mas isso não é motivo para que os já adultos não consigam se incluir e usar também com certa desenvoltura todas as ferramentas que julgarem necessárias para desenvolver suas ações no dia a dia.

Realmente as formas de comunicação estão se alterando. Em relação à afirmação anterior, Silva (2008, p. 51) comenta que há "avanços tecnológicos que encurtam tempo e distância e que, consequentemente, transformam os diversos processos e modos de produção e de comunicação, informação e tecnologia mudando constante e aceleradamente". Logo os meios de comunicação estão cada vez mais se transformando e o que era 
enviado por carta hoje em dia é enviado por e-mail, e o recebimento da mensagem é imediato, basta a pessoa estar conectada para visualizá-la.

Perante a todas essas transformações, encontra-se a escola centrada em base tradicionalista de transmissão de conhecimento e controle. Com as inovações tecnológicas, surge a necessidade da busca de um conhecimento que evolui, ou seja, está em constante transformação. Em relação a esses comentários, Silva (2008) nos afirma que estamos em crise:

Penso que a crise da educação e, por assim dizer, da ciência, reside exatamente no descompasso entre a noção de verdade moderna e as formas de conhecimento que as novas tecnologias engendraram na sociedade. Vale dizer que, com as novas tecnologias, o lugar do saber se descentraliza e se expande, fazendo com que o conhecimento esteja em todo o lugar e em nenhum lugar. A espacialidade do saber que a escola monopolizava se esvai. Ela perdeu o controle e a disciplina que a fundamentou. Temos que repensar o estatuto da educação numa sociedade de incertezas e não procurar modelos redentores e salvacionistas baseados em grandes promessas que não podemos controlar e cumprir (SILVA, 2008, p. 22).

A escola precisa se reestruturar e contribuir para prover um ser mais colaborativo e dinâmico, que desenvolva melhor suas habilidades com o intuito de aprimorar seu conhecimento através da interação com as novas ferramentas tecnológicas e a sociedade atual. Recai-se naquela velha frase: "não existe uma receita pronta”. E diante disso há uma imersão na crise e nas incertezas, esquecemos os grandes pensadores até porque eles não viveram nesta época de grandes mudanças tecnológicas. Pelo menos pra isso serviram as inovações tecnológicas, porque ficar décadas tematizando o ensino em ideias de pensadores não melhora em nada a prática de sala de aula. Pois a cada nova teoria, inúmeros adeptos a seguiam e em seguida vinha a derrocada, como foi o caso do Construtivismo. $\mathrm{O}$ autor referenciado anteriormente nos fala um pouco mais sobre o que estamos vivendo neste mundo contemporâneo quando nos diz: 
Vivemos uma época do presente, uma época da velocidade, uma época de quebrar recordes, de diminuir o espaço e subordiná-lo ao tempo. Uma época da informação, da imagem, do ecrã, do satélite, da fibra ótica, do cartão magnético, da virtualidade e da Internet... O que temos que enfrentar são esses novos elementos que dilatam nossa época e impõem uma nova percepção do mundo: do espaço, da linguagem, da ética, da responsabilidade, dos valores e do conhecimento... (SILVA, 2008, p. 23).

Realmente é tudo tão rápido que fica difícil acompanhar todos os avanços, quando parece que estamos entendendo, surgem inovações que novamente temos que aprender a usar. E na escola o que isso ocasiona? Todas essas mudanças alteram os interesses do aluno e são refletidas no comportamento em sala de aula, a qual ainda apresenta a mesma disposição e materiais de muitos anos atrás, tudo a volta evoluiu, mas a educação continua a passos de tartaruga. Frente a isso, Silva nos diz:

A falta do reconhecimento da autoridade do professor e de sua profissão pela sociedade contemporânea revela a falência da noção de autoridade e, portanto, do saber. Nossa sociedade vê o professor como um médium a mais. Ele, assim como a televisão, perdeu o monopólio da informação para os outros media. O método de ensino não acompanha a velocidade das mudanças e novidades que surgem a cada momento. $\mathrm{O}$ aluno, por sua vez, perde o encantamento com o estudo formal e com a sala de aula (SILVA, 2008, p. 30).

Verifica-se que a tecnologia transformou todos os setores da sociedade, em particular, a educação, em que papéis tradicionais como o professor detentor de todo o conhecimento já não existe mais e aquele docente que ainda persistir nesses ideais, provavelmente perderá o encantamento de seus alunos pelas aulas. Pois as tecnologias possibilitam a informação imediata e atual e com isso gerou um grande desafio; não apenas aos alunos, mas principalmente ao professor que precisa assumir um papel fundamental como mediador das aprendizagens, ensinando os alunos a navegar entre inúmeras informações, selecioná-las de maneira crítica e organizá-las. 


\section{Metodologia}

Este trabalho utilizou-se da técnica de levantamento bibliográfico bem como pesquisa do tipo quantitativa, através de questionário estruturado, impresso e distribuído ao públicoalvo com o intuito de conhecer a realidade de uso da informática como recurso de aprendizagem na educação escolar. A pesquisa foi destinada às pessoas que têm uma visão global do assunto e possuem meios para contribuir na melhoria dessas condições. Assim, são aquelas pertencentes à equipe diretiva: direção, supervisão e ou orientação, bem como os monitores de informática na escola que vier a tê-los. Foram oferecidos dois questionários diferentes: o primeiro a ser respondido pelo diretor e o segundo pelas pessoas da supervisão e pelos monitores de informática.

Para a realização do questionário foram visitadas escolas da região de Passa Sete e Sobradinho, totalizando dez escolas, sendo cinco na rede estadual e cinco na rede municipal. A referida pesquisa reforça a importância de conhecer a realidade das escolas, para assim contribuir na elaboração de artigo sobre o uso das tecnologias em sala de aula. Os questionários foram introduzidos de maneira concisa, salientando-se a importância da pesquisa e reforçando-se a necessidade de que as respostas expressassem bem a realidade da escola. Foi estipulado como prazo uma semana para o preenchimento e devolução dos questionários.

\section{Resultados}

Quanto à formação profissional dos entrevistados quatro diretores possuem pós- graduação em gestão, outros quatro possuem graduação e dois ainda estão cursando. Em relação à área pedagógica das escolas foi constatado que oito especialistas possuem Gestão Escolar, uma com licenciatura em Letras Português. Uma escola estadual iniciou o ano letivo sem supervisora. Em relação aos monitores de informática até o momento da 
pesquisa, início do ano letivo, só havia em duas escolas: uma da rede estadual e outro na rede municipal, respectivamente cursando especialização em Mídias na Educação e com Curso Técnico em Informática. Por informação de diretores, na rede municipal de Sobradinho seriam contratados monitores capacitados para todas as escolas.

Em relação ao questionário oferecido aos diretores de escola, a primeira questão solicita o $\mathrm{n}^{\mathrm{O}}$ de docentes que participou ou participa de estudos na área de informática. Conforme as informações, as escolas apresentam um, dois, dois, dois, três, quatro, cinco, seis, doze, vinte educadores. Veja a Figura 1:

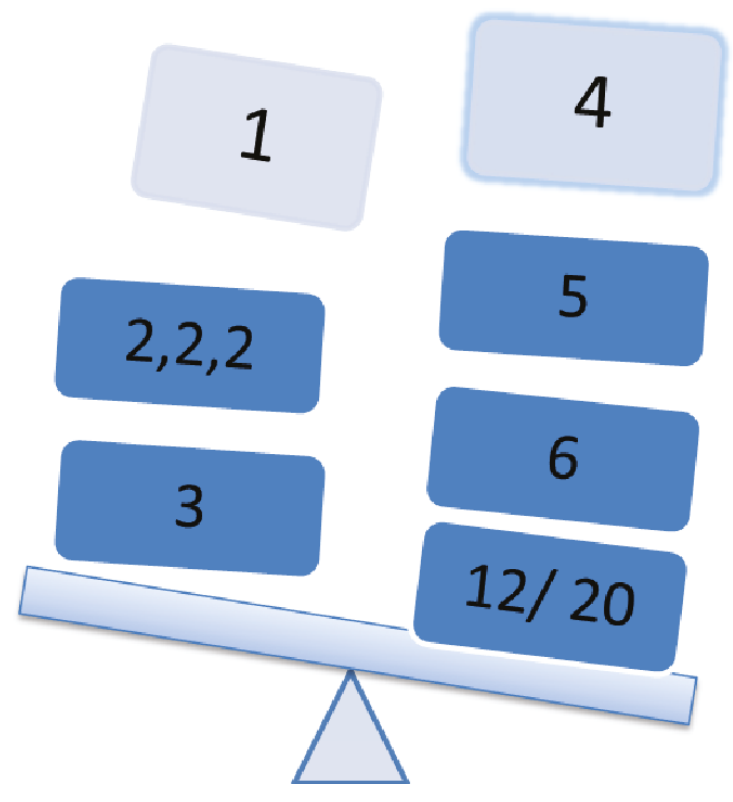

Figura 1: Docentes na área de informática.

Pôde-se perceber que o maior $\mathrm{n}^{\mathrm{o}}$ de docentes que frequentam cursos sobre esse assunto foi em uma escola municipal de 
Sobradinho, seguida pela escola estadual da sede de Passa Sete. Mediante a pesquisa, pôde-se constatar também que em todas as escolas analisadas existem profissionais que se dedicam a ampliar seus conhecimentos na área de informática.

A segunda questão pede a informação sobre a escola possuir laboratório de informática com acesso à Internet. Dentre as pesquisadas apenas uma localizada no interior de Passa Sete, da rede estadual, não possui laboratório com acesso à WEB. Provavelmente pela dificuldade de conexão, visto que em alguns locais do município até mesmo o celular fica fora da área de cobertura, por falta de sinal. Observe o Gráfico l:

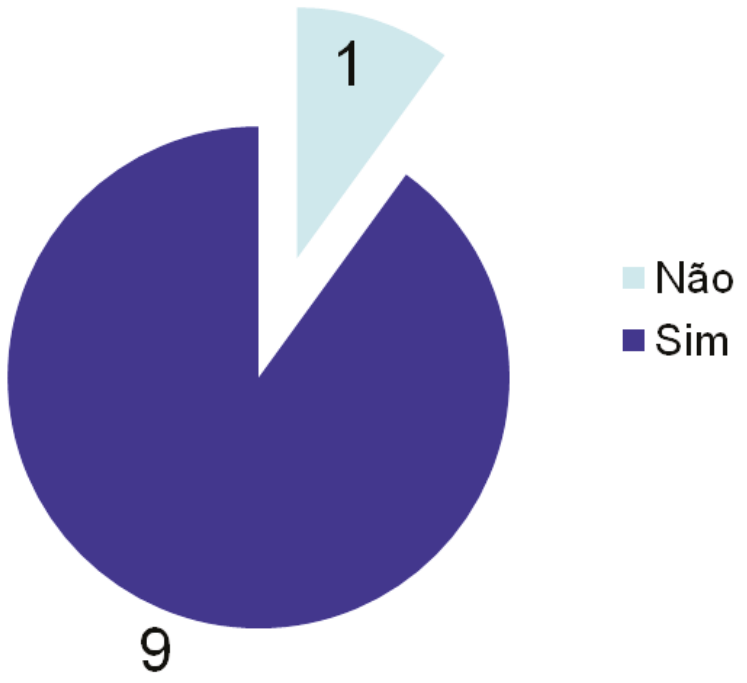

Gráfico 1: Escolas com laboratório e acesso à Internet.

Ainda em relação ao item dois é solicitada uma descrição do uso, condições, acesso e qual o profissional que oferece o atendimento no laboratório de informática. Sobre esses dados, 
dentre as escolas estaduais pesquisadas, somente a escola da sede de Passa Sete, além do acesso provido pelos professores em suas aulas, possui monitoria especializada nos três turnos semanais, uma vez por semana, sendo que o aluno de um turno faz o uso do laboratório em outro turno que não tiver aula. Frente a isso, todas as escolas estaduais informaram que todos os profissionais da escola podem oferecer o atendimento no laboratório, sendo responsabilidade do docente o planejamento e cuidados no uso. O maior número de computadores à disposição foi encontrado em uma escola estadual de Sobradinho, num total de vinte e seis computadores que utilizam o sistema operacional Windows e Linux. Nas demais escolas oferecem somente o Linux. Esse é um sistema que muitas vezes é de difícil uso quando utilizado para realizar outras tarefas além de pesquisas, talvez por falta de conhecimento dos usuários.

Em relação às escolas municipais, é oferecido monitor com curso técnico em informática para as aulas do laboratório. Há um cronograma de horários por turma, no mural da sala dos professores para o atendimento no laboratório. No entanto, na rede municipal de Passa Sete, o referido profissional é utilizado para a manutenção dos equipamentos e não é o responsável pelo acompanhamento dos alunos, o qual é feito por professores de outras disciplinas. Alguns diretores comentaram sobre a lentidão no acesso à Internet, bem como sobre a falta de computadores, insuficientes para a quantidade de alunos, o que restringe o uso, já que as turmas são grandes.

A terceira questão solicita comentários sobre o uso da informática em projetos pedagógicos na escola. Dentre as pesquisadas, duas escolas estaduais e uma municipal assinalaram que não usam. Foi relatado a falta de conhecimento dos professores, além da dificuldade de acesso à Internet. As demais escolas utilizam para pesquisa e desenvolvimento de outros projetos que necessitam o uso de Power Point. No entanto, na escola estadual da sede de Passa Sete há o projeto "Festival de Mídias", o qual em 2011 está em sua terceira edição. Esse projeto envolve professores da 
área de linguagens da escola e em cada turno possui um coordenador. Os alunos deverão formar um grupo e produzir um trabalho, filmado ou não, envolvendo uma obra literária lida. Para os alunos a partir da quinta série, esse projeto não utiliza o horário normal das aulas, mediante ao solicitado cada grupo de alunos produz seu trabalho e pode utilizar o laboratório com a assistência do monitor para sua montagem. Já em uma escola municipal de Sobradinho há o projeto "Informática na Educação", em que os alunos fazem o uso de apostilas com o intuito de compreenderem os princípios básicos no uso da informática e com isso servir de apoio ao processo de ensino-aprendizagem. Observe essas informações no Gráfico 2:

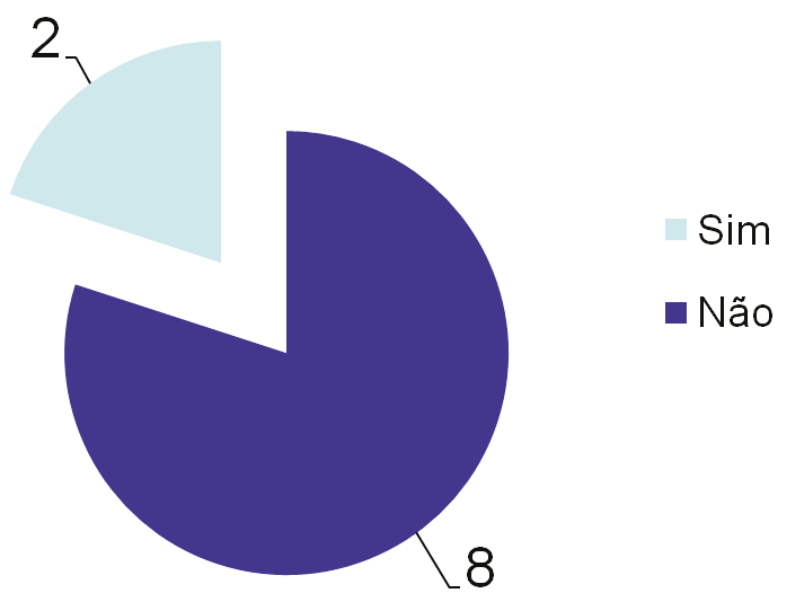

Gráfico 2: Uso da informática em projetos pedagógicos.

Em relação à questão quatro, que evidencia o uso do laboratório de informática pelos professores em sua prática pedagógica, foram assinalados por sete vezes o item "alguns", já a 
assertiva "sim" por duas vezes e somente uma escola assinalou o item "não". Com esse resultado, percebe-se que na maioria das escolas nem todos os professores fazem uso do laboratório de informática no planejamento de suas aulas.Veja o Gráfico 3:

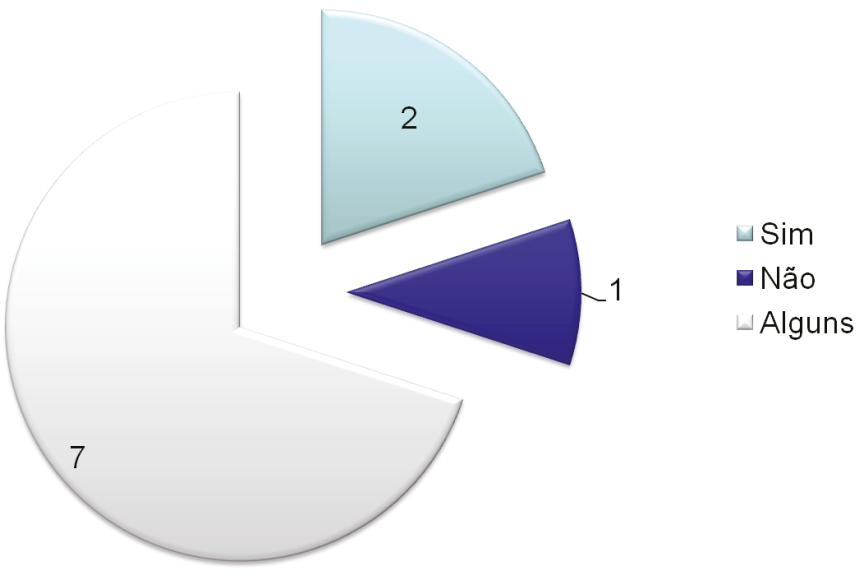

Gráfico 3: Uso do laboratório de informática pelos docentes.

Quanto à questão cinco que solicita assinalar as estratégias utilizadas pelos professores em relação ao uso das novas ferramentas tecnológicas em suas práticas, teve um maior percentual o item relacionado aos jogos educativos tendo sido assinalado por todos os diretores. Seguido dos itens: jogos de entretenimento e pesquisa com assunto e endereço, pontuando nove marcações. Após foi assinalado, com seis marcações cada, os itens: pesquisa aberta e uso do Power Point. Já com cinco marcações os itens: outros softwares e uso do editor de textos. E com duas marcações os itens: download de músicas e uso de e-mail ou Orkut. Observe o Gráfico 4: 
Gráfico 4 - Gráfico demonstrativo do resultado de uso das ferramentas tecnológicas.

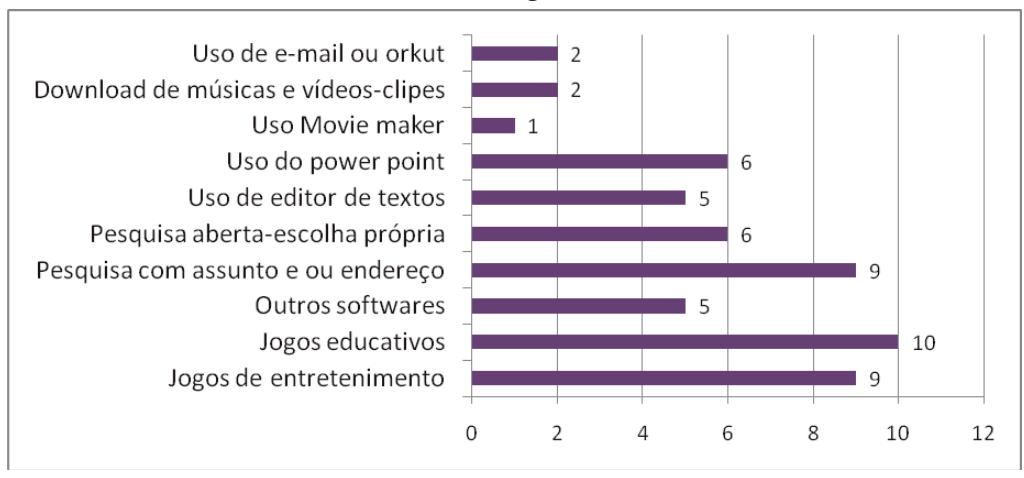

Quanto ao item e-mail e Orkut foi informado por equipes diretivas que o acesso é dificultado, pois algumas escolas quando abordaram o uso do laboratório comentaram que sites de relacionamento tinham sido bloqueados. Em relação ao uso do Movie Maker somente uma escola assinalou o item, por se tratar de um programa de edição de vídeos, podendo ser colocadas imagens, pequenas filmagens, escrever títulos e ainda usar o fundo musical escolhido para fazer a abertura dos títulos e término das apresentações.

Ainda em relação à pesquisa realizada, mas voltadas ao que nos revela os supervisores e monitores de laboratório de informática em relação ao uso da informática na educação, surgem as seguintes ideias e considerações. Num primeiro momento foi- lhes questionado o que era feito nas escolas para incentivar o docente em relação ao uso planejado das novas tecnologias, já com o intuito de fazer entender que a supervisão também tem uma fatia de compromisso com os educadores.

Perante a primeira questão foi respondido que "a escola não pode ficar aquém da sociedade com relação ao uso da tecnologia. Para tanto as escolas estaduais têm assessoramento através do NTE da Coordenadoria, no sentido de viabilizar cursos aos professores, bem como foi montado laboratórios de informática 
com o programa Linux em suas escolas de abrangência. Também foi comentado que os laboratórios de informática estão à disposição dos professores que desejarem aprender a operar hardwares como: impressora, scanner, CD, DVD, pen drive e softwares disponíveis como processador de texto e Internet". Realmente em escolas estaduais o NTE é parceiro, no que tange ao desenvolvimento de cursos e capacitação dos professores, em 2011 foram oferecidos treinamentos para uso de softwares como o Power Point e Movie Maker entre outros cursos. Além dos cursos providos pelo NTE em escolas estaduais, também foi mencionado a especialização em Mídias na Educação pela UFSM, seguindose sugestões e troca de ideias nas reuniões pedagógicas, cursos e treinamentos de formação. No entanto, houve supervisoras que comentaram que como incentivo ainda faltava muito, e o que deveria ser oferecido era uma formação em que o próprio docente pudesse explorar o uso das novas tecnologias como instrumento didático que despertasse a curiosidade e a busca do saber, tanto do aluno, quanto do professor. Talvez até pela falta desse envolvimento e capacitação, foi relatado ainda que há desmotivação por parte dos professores no uso das novas tecnologias.

Já em relação à questão dois que suscita informações de quais seriam os fatores principais de não uso das novas tecnologias pelos docentes temos reconhecido mediante o questionário respondido a falta e dificuldade de acesso à Internet, sinal ruim; bem como o número de máquinas insuficientes em relação ao número de alunos. Foi citado ainda falta de conhecimento, medo do novo e que alguns professores são reticentes em usar por não se sentirem preparados o suficiente, por comodismo ou por estarem acostumados a darem aulas mais tradicionais. Foi comentado ainda sobre a falta de tempo, uma vez que adotar tecnologias no processo ensino-aprendizagem é uma atividade complexa que demanda tempo e esforço para aprender e aplicar. Perante isso cabe acrescentar a essas informações e, diria até para fazer o fechamento da questão, o que foi escrito por uma supervisora municipal. Ela expressou em sua resposta que há a 
necessidade de que o professor esteja "disposto" a aprender a planejar, a romper as barreiras do novo, uma vez que nossos atuais cursos de graduação não nos habilitaram para o uso eficaz das novas tecnologias. Enquanto o exposto acima não for realizado, as novas tecnologias continuarão em desuso nas escolas.

Acerca da última questão, elaborada aos supervisores, a qual solicita que sejam comentadas estratégias pedagógicas usadas pelos professores em relação ao uso das novas tecnologias, foram relatadas algumas. Na escola estadual da sede de Passa Sete o Festival de Mídias, que nas duas primeiras edições incentivou os alunos a formarem grupos e produzirem um vídeo sobre temas variados, podendo apresentar entrevista, montagem de mensagem, vídeo produzido pelos alunos, peças teatrais como uma adaptação de Romeu e Julieta, só que na era moderna, slides de diversos assuntos tais como relacionados a cantores famosos, belezas do Rio Grande do Sul, sobre a era da informação, entre outros. Esse projeto era avaliado pelos professores coordenadores e projetado para toda a comunidade escolar em data marcada no calendário escolar. Em 2011, em função da separação dos projetos voltados a cada área do conhecimento, houve alteraçôes e ele, em sua terceira edição, passou a ser solicitado que fosse feito baseado em uma obra literária, até para incentivar a leitura. O referido projeto é apresentado à comunidade escolar em data agendada para a apresentação nos três turnos de aula e avaliado pela professora coordenadora de cada turno e demais professores da área de linguagens. Esse projeto se encontra em pleno desenvolvimento e continuará a ser desenvolvido na escola, uma vez que os alunos aguardam ano a ano a mostra dos seus trabalhos e visualização dos vídeos dos demais alunos. Cabe ainda comentar que em datas próximas à apresentação dos trabalhos, o laboratório de informática é reservado para os alunos que precisam concluir seus trabalhos e necessitam ajuda do monitor.

Em outra escola estadual, agora da rede de Sobradinho, é desenvolvido o projeto de Iniciação às ferramentas tecnológicas voltadas à educação, com a participação de monitoria para 
pesquisa com ambiente adequado, utilizando-se 26 máquinas com softwares educacionais acessados a partir da Internet.

Em relação a escolas municipais, além do projeto Informática na Educação que instrui alunos através de apostilas com conhecimentos básicos de informática, as demais informaram que não possuem projeto na área de informática, porém comentaram que usam o laboratório de informática para pesquisas de acompanhamento de fenômenos naturais ocorridos no planeta (vulcões, terremotos, tsunamis, posição do sol em relação aos continentes) bem como uso de softwares educativos diversos. Foi relatado ainda que os eventos da escola como Feira de Ciências usa o laboratório de informática para pesquisas e montagem de pequenos vídeos que são editados na escola e mostrados, através de data show, para a comunidade escolar como uma retrospectiva do que foi desenvolvido com os alunos durante o ano letivo.

\section{Considerações finais}

Mediante a pesquisa realizada, foi possível constatar que na maioria das escolas, fica livre o uso ou não das novas tecnologias como ferramenta para melhorar o ensino e aprendizagem dos alunos, uma vez que cada professor mediante o seu interesse pode levar os discentes para o laboratório de informática de acordo com a sua necessidade. A maioria desses laboratórios não possui profissional capacitado para auxiliar o professor no desenvolvimento de um trabalho mais dinâmico no uso das novas tecnologias.

A pesquisa apontou serem necessários esclarecimentos para os professores no laboratório de informática da escola com o próprio monitor capacitado, priorizando os elementos básicos de uso do computador, seus programas e hardwares, bem como apresentando dicas de trabalho. E preciso mais informações técnicas para que o professor, ao planejar suas aulas e com o conhecimento que adquiriu, possa imaginar formas de integrar as possibilidades que as novas mídias proporcionam, contribuindo para ampliar 
o seu trabalho e melhorar as aprendizagens dos alunos. Logo nos ambientes em que houver monitor com o curso Técnico em Informática, deveria haver uma integração no planejamento das aulas entre o professor responsável pela turma e o monitor do laboratório, juntando-se assim o técnico com o pedagógico.

Diante disso e de inúmeros fatores que acometem o uso da informática como ferramenta para auxiliar na aprendizagem, há uma grande barreira que para ser transposta precisa do envolvimento de todos da escola. Inovar é inviável de uma hora para outra; tendo professores da era da máquina de datilografia, com carga horária cheia, turmas grandes e ainda permeadas por alunos que vêm à escola sem interesse e muitas vezes com o intuito de passar o tempo e não ajudar os pais em casa.

É necessário transformar a educação, seguimos o mesmo modelo e programa há anos, altera-se a ordem dos conteúdos, mas mudanças não são sentidas. Talvez a solução esteja no uso planejado das novas tecnologias e isso só se daria em sua essência se fosse abraçada por todos na escola de forma integrada em seu currículo.

Para que essa realidade se transforme é preciso formação do profissional no uso das novas mídias permitindo-lhe meios para repensar sua prática e perceber quando for necessário o uso das ferramentas tecnológicas, através da reflexão conjunta e do bom uso das tecnologias com o intuito de preparar os alunos para assumir seu verdadeiro papel na sociedade tecnológica do conhecimento e da informação.

Comentando os dados da pesquisa no que tange às diferenças de ensino no sistema municipal e estadual constatei que a rede municipal tem autonomia para a contratação de profissional capacitado e com carga horária suficiente para desenvolver aulas de aperfeiçoamento e aprendizagem na área de informática. Sendo assim, a rede municipal consegue ministrar aulas além das oferecidas pelo professor da disciplina com monitoria especializada ou não. Já os projetos oferecidos são voltados para o ensino de conhecimentos básicos no uso do computador. 
Na rede estadual ainda não é permitido contratar profissional capacitado para trabalhar especificamente no laboratório de informática. Como não há horários de aulas de informática além das oferecidas aleatoriamente pelos professores em suas classes, alguns docentes buscam adquirir conhecimentos nessa área mediante a participação em cursos oferecidos gratuitamente pelas coordenadorias estaduais. Com isso são agentes dentro da escola na promoção de ações que facilitem um maior número de alunos na interação com as novas tecnologias e no desenvolvimento de projetos teóricos e práticos de uso das tecnologias em situaçôes que os alunos são os protagonistas de suas ações.

Com isso, pode-se constatar que mesmo a escola não possuindo monitor de laboratório em tempo integral, mas tendo um projeto voltado para o uso das tecnologias o aluno busca ampliar seu conhecimento e produzir algo que vá além de cartazes. Grande parte disso está sendo desenvolvido no projeto III Festival de Mídias que acontece na E. E. Educação Básica Cristo Rei, coordenado pelos professores da área das linguagens e que envolve a leitura de obras literárias, dramatizações e filmagens das mesmas.

Além de projetos que envolvem as áreas específicas do conhecimento, cada professor pode desenvolver atividades que contextualizem o aluno com a sociedade tecnológica que estamos vivendo, promovendo ambientes de descoberta e investigação mediante o conteúdo a ser estudado e o que se encontra na Internet, tornando a aprendizagem mais realista, conhecendo diferentes culturas, visualizando obras de arte e uma variedade de ferramentas para guardar informações. O professor pode criar com a turma um ambiente onde os alunos podem se comunicar através de e-mails com outros estudantes, ou então atividades e/ ou resumos das aulas que dão suporte à aprendizagem dos alunos, bem como criar um blog da turma para os pais estarem a par dos trabalhos desenvolvidos ou para possíveis comunicados da escola.

Apesar das dificuldades apresentadas no uso das ferramentas tecnológicas, temos condições, nem que sejam mínimas, de 
planejar o ensino utilizando as novas tecnologias. Ressalta-se, ainda, a importância que tem para a escola e seus professores os cursos e especializações promovidos pelos setores de informática das Coordenadorias Estaduais e parcerias com instituiçôes como a UFSM. É principalmente a partir deles que os professores têm acesso, uso e capacitação adequados na introdução das novas tecnologias em suas aulas, seja por meio de projetos, pesquisas e produção de trabalhos midiáticos, por exemplo.

\section{Referências}

COSCARELLI, Carla Viana; RIBEIRO, Ana Elisa. (Orgs.). Letramento digital: aspectos sociais e possibilidades pedagógicas. Belo Horizonte: Ceale; Autêntica, 2005.

MARTINS, Francisco Menezes; SILVA, Juremir Machado (Orgs.). Para navegar no século XXI: Tecnologias do imaginário e Cibercultura. Porto Alegre: Sulina/Edipucrs, 2000.

MERCADO, Luis Paulo (Org.). Novas Tecnologias na educação: Reflexões sobre a prática. Maceió: EDUFAL, 2002.

NEVES, Ricardo. O novo mundo digital: você já está nele: oportunidades, ameaças e as mudanças que estamos vivendo. Rio de Janeiro: Relume Dumará, 2007.

PRETTO, Nelson de Lucca. Além das redes de colaboração: Internet, diversidade cultural e tecnologias do poder. Salvador: EDUFBA, 2008.

SILVA, Mozart Linhares. Novas tecnologias - educação e sociedade na era da informação. Belo Horizonte: Autêntica, 2008.

KONRATH, Mary Lúcia Pedroso et al. Objetos de Aprendizagem, Formação de Professores e Práticas Pedagógicas no Contexto Escolar das Séries Iniciais. In: NEVADO, Rosane Aragón de; CARVALHO, Marie Jane Soares de; MEDEIROS, Crediné Silva de (Org.). Aprendizagem em rede na educação à distância: estudos e recursos para a formação dos professores.1 ed. Porto Alegre: Ricardo Lenz Editor, 2008, v. 1, p. 131149. 


\section{ANEXO I}

UNIVERSIDADE FEDERAL DE SANTA MARIA

- UFSM

PÓS GRADUAÇÃO EM MÍDIAS NA EDUCAÇÃO MONOGRAFIA - EAD

INSTRUMENTO DE PESQUISA:

QUESTIONÁRIO SOBRE A UTILIZAÇÃO DA INFORMÁTICA COMO RECURSO DE APRENDIZAGEM NA EDUCAÇÃO ESCOLAR

Prezado(a) educador(a):

Solicito que responda as questões deste questionário de forma a expressar a verdadeira realidade de sua escola. Destaco que sua identidade será sempre preservada quando me referir ou apresentar dados obtidos através da pesquisa. Desde já agradeço sua colaboração e participação.

Informaçôes Gerais:

Data: Escola:

Nome:

Rede? ( ) municipal ( ) estadual

Formação Profissional:

Função que desempenha na escola:

\section{QUESTIONÁRIO 1 (direção escolar)}

Sua escola possui docente que participou ou participa de estudos na área de informática?
a. ( )sim, quantos?
b. ( ) não 
Sua escola possui laboratório de informática com acesso à Internet?
a. ( ) sim
b. não

Por qual profissional é oferecido o atendimento no laboratório? Descreva como é o acesso, o uso e as condições do laboratório de informática de sua escola:

Sua escola utiliza em seus projetos pedagógicos o uso da informática?
a. ( ) $\operatorname{sim}$
b.( )não

Teça seus comentários sobre o uso:

Os professores em sua prática pedagógica utilizam o laboratório de informática como ferramenta de ensino?
a. ( ) sim
b. ( )não
c. ( ) alguns

Assinale as estratégias utilizadas pelos professores de sua escola em relação ao uso das novas ferramentas tecnológicas em suas práticas:
a. ( ) jogos de entretenimento;
b. ( ) jogos educativos;
c. ( ) outros softwares educativos;
d. ( ) pesquisa com assunto e ou endereço;
e. ( ) pesquisa aberta- escolha própria;
f. ( ) uso de editor de textos;
g. ( ) uso do Power Point;
h. ( ) uso do Movie Maker;
i. ( ) download de músicas e ou vídeo-clipes;
j. ( ) uso de e-mail ou orkut; 

lab.)

QUESTIONÁRIO 2 (supervisão escolar e monitor de

O que é feito para incentivar o docente em relação ao uso planejado das novas tecnologias?

O que você determina como sendo fator principal de não uso das novas tecnologias pelos docentes em sua escola?

3. Você tem conhecimento sobre as estratégias pedagógicas planejadas e usadas pelos professores de sua escola que englobam o uso de ferramentas tecnológicas? Teça comentários sobre: (descreva algum projeto que a escola desenvolve voltado para o uso das novas tecnologias) 